\title{
RESSIGNIFICAÇÃO, CONSUMOS E SILÊNCIOS DA COZINHA DOMÉSTICA
}

\author{
Resignification, consumption and silence in home kitchens
}

\author{
Felipe Gouvêa Pena* \\ Luiz Alex Silva Saraiva**
}

\section{RESUMO}

A avalanche de comerciais e programas televisivos promovendo uma cozinha esteticamente superior e repleta de produtos que facilitam o processo de cozinhar tem ajudado a ressignificar a cozinha tradicional. Neste artigo o objetivo é analisar a ressignificação material e simbólica pela qual a cozinha doméstica vem passando. Para isso foi feito um estudo baseado em método indutivo de abordagem qualitativa que usou entrevistas semiestruturadas com patrões e patroas, donas de casa e empregadas domésticas. Os dados coletados foram tratados por meio da análise do discurso, adequada à exploração de enunciados discursivos oriundos de distintos grupos sociais. Os principais resultados sugerem que, para além do consumo, a cozinha, para as mulheres, permanece como um espaço compulsório de trabalho, ao passo que, para os homens, trata-se de um espaço no qual promovem "espetáculos gastronômicos". As principais contribuições que problematizam os atributos dessa nova cozinha investem em um falso antagonismo entre tradição, simplicidade e feminino, e inovação, sofisticação e masculino, em um espaço que atrai os homens ao distanciá-los da rotina e da obrigatoriedade de cozinhar, mantendo, para eles - e apenas para eles - a herança patriarcal de poder escolher se, como, quando, onde e para quem cozinhar.

Palavras-chave: Cozinha Doméstica. Relações Sociais de Gênero. Movimento Gourmet. Espetáculo.

\section{ABSTRACT}

The avalanche of commercials and television programs promoting an aesthetically superior kitchen, filled with products that facilitate the cooking process has helped to reframe the traditional kitchen. In this paper, our goal is to analyze the material and symbolic resignification that the home kitchen is undergoing. In order to achieve this goal, a study based on the inductive method of a qualitative approach with semi structured interviews with employers, housekeepers, housewives and maids was carried out. The data collected were treated through discourse analysis, suitable for the exploration of utterances from different social groups. The main results suggest that, beyond consumption, for women the home kitchen remains as a compulsory space of work, whereas for men, it is an occasional space in which they promote "gastronomic spectacles". The results of the study contribute to the problematization of the fact that the attributes of this new kitchen are based on a false antagonism between tradition, simplicity and feminine on the one hand, and innovation, sophistication and masculine, on the other hand, in a space that attracts men by distancing them from the routine and the compulsory nature of cooking, keeping for them - and just for them - the patriarchal heritage of being able to choose whether, how, when, where and for whom to cook.

Keywords: Home Kitchen. Gender Social Relations. Gourmet Movement. Spectacle.

\footnotetext{
* Mestre em Administração pela Universidade Federal de Minas Gerais (UFMG). Pesquisador do Centro de Pós-graduação e Pesquisas em Administração da Universidade Federal de Minas Gerais (UFMG). Professor dos Cursos de Graduação do Centro Universitário de Belo Horizonte (UNIBH) - Belo Horizonte (MG), Brasil. E-mail: felipegouveap@hotmail.com. ORCID: 0000-0002-3730-1021

** Doutor em Administração pela Universidade Federal de Minas Gerais (UFMG). Professor do Centro de Pós-graduação e Pesquisas em Administração na Universidade Federal de Minas Gerais (UFMG) - Belo Horizonte (MG), Brasil. E-mail: saraiva@face.ufmg.br. ORCID: 0000-0001-5307-9750
} 


\section{INTRODUÇÃO}

O movimento de gastronomização do cotidiano alimentar constitui um processo de endogenização da estética da vida cotidiana para grande parte da população. Ele assinala a passagem do ato cotidiano de alimentação - rotineiro, quase automático, e hoje com uma dimensão política - a uma ação ritualizada, envolvendo aspectos de prazer sensorial, comensalidade e sociabilidade nunca vistos (BARBOSA, 2012; BOUTY; GOMEZ, 2013). Conforme Floyd (2004, p. 71), não é possível, contudo, desconsiderar a cozinha como um espaço no qual acontecem inúmeros problemas culturais, políticos e econômicos que atribuímos a outros espaços domésticos: “[...] a cozinha que vemos não é 'apenas' ou necessariamente um espaço doméstico. Muitas vezes tem uma qualidade mais ambígua, indistinta, nem decisivamente contextualizada nem limitada pela necessidade de parecer completamente real". Isso a qualifica em termos organizacionais e, assim, para este artigo.

Nessa era da "gourmetização", um produto não precisa ser de fato exótico, ter origem e preparo singulares ou mesmo contar com ingredientes sofisticados. Com um simples toque "mágico", o seu rótulo se transmuta em um poderoso adicional simbólico: basta ser denominado gourmet (ou premium, chic, top, entre outros), que se cobra muito mais por ele. Ao inserir tal "valor agregado", o modismo da vez é servido a um exército de consumidores insaciáveis (MARTENS; SCOTT, 2006). Das "pizzas gourmet" à "febre das cervejas premium", o Brasil se vê diante de uma expressiva mudança conceitual, estampada em embalagens pérfidas e emanadas pelos discursos do nouveau riche. Além disso, "[...] o trabalho dessas cozinhas é evidentemente distanciado das relações de lar ou da responsabilidade rotineira de alimentar as pessoas" (FLOYD, 2004, p. 63), um silêncio sobre a cozinha real e suas características. Todavia, esse fenômeno tem atingidodiferentes classes sociais e é uma tendência que ele se amplie, já que há um crescente esforço midiático nesse sentido.

Defende-se aqui o argumento de que a valorização recente da cozinha doméstica e, por consequência, do ato de cozinhar - o que não deixa de atestar uma ressignificação desse espaço - tem ocultado questões históricas da sociedade brasileira. Considerando aspectos concretos, mas, principalmente simbólicos, entende-se que às mulheres (donas de casa e empregadas domésticas) foi concedida a "posse" da cozinha, sem que para isso tenham sido previamente consultadas. Os homens, por sua vez, historicamente vinculados ao espaço público, vêm se apropriando da cozinha em meio aos discursos midiáticos do movimento gourmet, que os valorizam, os exaltam e Ihes concedem o título de "donos da cozinha". Háuma inevitável discussão de relações sociais de gênero nesse território, muitas vezes silenciada.

Em uma rápida reflexão, não é difícil recordar discursos que hoje exaltam a ida do homem para a cozinha doméstica - como o de que "ele me ajuda a fazer comida" - ou dos próprios homens em "brincar" de ser chef em momentos específicos, como em festas, onde o "aplauso" é garantido. 0 ingresso do homem nesse ambiente tende a silenciar que esse espaço da casa sempre foi destinado à mulher e que, em uma sociedade machista como a brasileira, a aproximação dos homens com o ato de cozinhar sugere um processo de ressignificação. 
Corroborando com Dória (2012) sabe-se que empiricamente a "mulher na cozinha" é uma categoria oposta ao "homem na cozinha", o que reflete uma condição de diferenciação baseada em níveis complexos da cultura social. Logo, a divisão sexual e social do trabalho se transforma a partir das "[...] diferentes culturas e épocas, reordenando as hierarquias de gênero. Mas o que nos interessa é detectar onde passa a residir o "feminino" quando o cozinhar se "desfeminiliza", isto é, se projeta na sociedade como campo masculino" (DÓRIA, 2012, p. 253).

O que se deseja problematizar observando o caso brasileiro, contudo, não é exclusividade do nosso país. Floyd (2004, p. 61), referindo-se ao contexto britânico, destaca que "[...] enquanto o significado de outros espaços tem de ser continuamente renegociado, a cozinha mantém a sua reputação como um espaço ideologicamente carregado, inequívoco no sentido e impermeável à mudança", um espaço de opressão das mulheres. Na França, de acordo com Giard (2009, p. 212), a atribuição à mulher do ato de cozinhar é equivocadamente associadaa uma "manifestação da essência feminina". A cozinha constitui uma "[...] zona de sujeição feminina, onde as mulheres devem gerir uma rotina incessante de trabalho para a satisfação das pessoas acima delas na hierarquia doméstica, social e política" (FLOYD, 2004, p. 62). Meah (2014), ao tratar de subjetividades e gênero em espaços de cozinha domésticos no norte e no sul globais, observou que, apesar de condições relativamente melhores nos Estados Unidos, Nova Zelândia, e Austrália, a cozinha é mais opressora sobre mulheres negras e de minorias étnicas estadunidenses, o que também vale para o Quênia, Sudão do Sul, África do Sul, México, Chile, Bolívia, Peru e Índia.

Considerando este contexto, nesse artigo o objetivo é analisar a ressignificação material e simbólica pela qual a cozinha doméstica vem passando, o que foi feito por meio de um estudo baseado em um método indutivo de abordagem qualitativa junto a empregadas domésticas, donas de casa, patroas e patrões, partindo-se do pressuposto de que esses sujeitos vivenciam, constroem e se apropriam da cozinha doméstica de formas distintas. Além desta introdução, o texto está organizado em mais cinco seções: a proximidade das mulheres - e o distanciamento dos homens - do mundo doméstico, a cozinha gourmet e suas facetas, escolhas metodológicas, análise dos resultados e considerações finais.

\section{A PROXIMIDADE DAS MULHERES - E O DISTANCIAMENTO DOS HOMENS - DO MUNDO DOMÉSTICO}

Entende-se que o trabalho doméstico e, em especial, as práticas realizadas na cozinha ainda são atribuídas às mulheres, pois as relações sociais, econômicas, políticas e culturais ainda vivenciam as premissas do patriarcado. Essa delimitação de papeis não deve ser atribuída apenas a um sistema, como se ele tivesse vida própria, bem como o território não pode ser tomado como algo neutro, existe uma demarcação e uma imposição ideológica que se ampara no conjunto das práticas sociais (LEFEBVRE, 1991). Afinal, "[...] mesmo que exista delegação, um de seus limites está na própria estrutura do trabalho doméstico e familiar: a gestão do conjunto do trabalho delegado é sempre da competência daquelas que delegam" (HIRATA; KERGOAT, 2007, p. 607). Nesse sentido, a divisão do trabalho se desenvolve a partir de uma "consciência relacional" proporcionada pelo aumento da necessidade e dela própria, mesmo que inconsciente, de aumentar a produtividade e produzir 
uma severa divisão material e intelectual do trabalho (RIBEIRO; HANASHIRO, 2016). 0 desejo por tal separação e sua conclusão afeta diretamente as relações estabelecidas no âmbito privado (doméstico) e no público (profissional), evidenciando duas faces de uma única moeda, produção e reprodução.

Pateman (2010, p. 34) pontua que o "estranhamento" e o "distanciamento" dos homens das atividades domésticas é visível. Para ela, embora a maioria das mulheres nos países "brancos" seja uma parcela significativa do mercado de trabalho, elas ainda são as principais responsáveis pelas atividades domésticas e de cuidados. Os homens aproveitam a situação e se recusam a compartilhar as funções no âmbito privado, ignorando as atividades relacionadas à responsabilidade rotineira de alimentar pessoas (FLOYD, 2004). Uma das consequências, em conjunto com o desejo de se esgueirar dos conflitos conjugais, é a contratação da figura da empregada doméstica em algumas regiões (PATEMAN, 2010). Assim, em muitos casos, a "fuga" dos compromissos domésticos implica sua delegação à empregada doméstica, uma nova hierarquização das relaçõesque evidencia o patrão e a empregada.

Welzer-Lang (2004) investigou "a concepção dos afazeres domésticos", tendo constatado diferentes concepções, conforme o gênero, do que se entende sobre as atividades domésticas no ambiente privado: os homens possuem um comportamento curativo e as mulheres, preventivo. Em função da pressão do meio social e das normas estabelecidas culturalmente, as mulheres costumam estar sempre preocupadas com a limpeza e o zelo da casa, poisbuscam o reconhecimento como "boas donas de casa"; já os homens estariam "dispostos" a fazer as tarefas apenas quando percebessem a casa suja (BRUSCHINI; RICOLDI, 2012). Apesar de este ser um olhar sexista de mundo, é rotina de muitas famílias.

Esse cenário revela a permanência do "contrato sexual" problematizado por Pateman (1988). Fruto de relações de distinção como "família e política" e "público e privado", tal contrato silencia o lado "dominado" (a mulher) e legitima o discurso do dominante (o homem). Logo, noções capitalistas se materializam e fornecem justificativas para a manutenção das relações sociais. As premissas patriarcais e as ideologias que o encobrem permitem com que o trabalho masculino seja valorizado de uma forma diferente, deixando explícito que o trabalho qualificado é aquele exercido pelo sexo dominante (TACHINO, 2010).

Nos últimos anos, alguns fatores favoreceram maior visibilidade do trabalho realizado por uma grande massa de mulheres. Um delesse refere à mudança metodológica do IBGE em seus levantamentos, como incluir atividades para "autoconsumo" e aquelas no âmbito da produção familiar (NEVES, 2006). Porém, o trabalho doméstico realizado por muitas mulheres, e que contribui para a reprodução da sociedade, ainda é classificado como inatividade econômica. Como ressaltado por Hirata (1997, p. 19), "[...] as mulheres são as primeiras vítimas do paradoxo crescimento do emprego feminino num contexto de crise: menores salários, maior instabilidade, condições de trabalho acumulando atividades domésticas e profissionais, maior desemprego, impactos possíveis sobre a saúde", além de um tempo social reduzido. "As habilidades históricas das mulheres, sua competência, seu saber e sua inteligência no processo de cozinhar nunca receberam um melhor reconhecimento" (SILVA, 1997, p. 50).

Como descrito por Neves (2006) é importante salientar aspectos de permanência e de mudanças pelos quais passou o contingente feminino no mundo do trabalho, sendo 
necessária uma compreensão das relações sociais de gênero em um contexto mais amplo na sociedade. Investigar o modo pelo qual as mulheres incorporam e são incorporadas pelo mercado de trabalho significa observar as construções culturais e históricas permeadas pela dinâmica das relações sociais entre homens e mulheres, as representações e seus significados entre o que se toma por masculino e feminino. Tais relações advêm de interações no campo social, do trabalho, da família e de diferentes instituições, conformando subjetividades e identidades. Assim, as diferentes formas de discriminação são estabelecidas em decorrência de valores culturais arraigados, que transformam diferenças em condições de desigualdade e preconceito (NEVES, 2006). Assim, não é possível isolar o trabalho das mulheres no âmbito privado, "[...] como se ele não existisse e não contribuísse de forma decisiva para a manutenção do sistema econômico capitalista; também não há como circunscrever o homem somente no domínio da produção e isentá-lo de sua função na esfera doméstica" (RIBEIRO; HANASHIRO, 2016, p. 122).

\section{A COZINHA GOURMETE SUAS FACETAS}

Homens e mulheres sempre estiveram presentes na cozinha; porém, há uma distinção entre suas cozinhas, que não foram, não são e não serão as mesmas. Enquanto as mulheres foram destinadas às cozinhas das "casas", os homens se apropriaram das cozinhas da "rua", uma diferença entre as esferas privada e a pública. As mulheres cozinhavam em casa, para as famílias, ao passo que os homens em restaurantes, palácios de governo e outras esferas públicas (BARBOSA, 2012). A cozinha doméstica sempre foi um espaço "por excelência" da mulher, seja ela dona de casa ou empregada, um reduto ao qual não se atribuía qualquer valor (FLOYD, 2004). Historicamente, a cozinha foi colocada no fundo da casa como se houvesse um desejo de separação desse cômodo das demais dependências. Diversos aspectos sustentaram esse afastamento, como "[...] a existência de empregados, o cheiro da comida, a utilização do processo de fritura na culinária brasileira, o contato íntimo dos empregados com os problemas dos patrões por meio de conversas de mesa, tudo isso era invocado para que a cozinha fosse mantida à distância" (BARBOSA, 2012, p. 189). No entanto, a cozinha doméstica, bem como o "ato de cozinhar", vem sendo ressignificados, passando a ter destaque na vida cotidiana.

A decoração da cozinha, uma das mais caras de uma casa, é hoje objeto de demonstração dos donos, afirmação de status e da escolha de um estilo de vida (existe um velho hábito brasileiro, o de mostrar a casa para visitas). A cozinha ganhou uma decoração, processo diferente de ganhar uma mobília. Isto significa que ela tem um estilo. Além disso, virou o centro da sociabilidade e dos prazeres da mesa. Como se isso não bastasse, a cozinha avançou sobre as varandas como o famoso "espaço ou varanda gourmet" (BARBOSA, 2012, p. 189).

Conforme Ipiranga, Lopes e Souza (2016) é preciso considerar que o ato de cozinhar e se alimentar abriga um teor simbólico muito grande, já que a "leitura da cozinha" nada mais é do que uma "viagem na consciência" que todas as sociedades possuem de si mesmas. A forma como se interage com a cozinha diz muito sobre o estilo de vida de quem 
dela se apropria e a partir de quais condições e ocasiões isso ocorre. Há uma inevitável discussão sobre as interferências que essas relações podem causar no imaginário de um grupo, pois se entende que haverá mudanças e não apenas no Estado, mas, principalmente, nos sentidos que se atribui aquele território e a aquelas práticas. A prática culinária reflete um conjunto de sistemas específicos de uma determinada cultura e envolve sensações, emoções e lembranças a que cada indivíduo esteve sujeito em suas vivências. Portanto, preparar e consumir um alimento tende a despertar diferentes significados e motivações, sendo sempre pertinente considerar que há um "juízo estético" por parte das pessoas, e isso não pode ser negado, já que a valorização do ato de cozinhar está ligada a entender a prática como uma atividade artística que solicita um nível de reconhecimento (IPIRANGA; LOPES; SOUZA, 2016, p. 206).

Lívia Barbosa, em "Os donos e as donas da cozinha" (2012), frisa que esse processo de estetização da cozinha é uma tendência não apenas para os segmentos mais altos da sociedade, atinge também as camadas de renda mais baixas. Se as pessoas de menor poder aquisitivo não podem ter uma cozinha gourmet, utilizam diferentes mecanismos para viver esse processo midiático, seja fazendo uso dos espaços gourmet na área comum dos prédios, que cada vez mais contam com esses espaços, seja pela aquisição de produtos associados a uma gastronomia refinada e com um valor (simbólico) agregado. A autora ressalta que as lojas especializadas na venda destes utensílios dispõem seus produtos e serviços com preços acessíveis, permitindo ao consumidor integrar-se ao movimento gastronômico.

Conforme Scavone (2008) ao refletir sobre gênero e suas interações com o campo da gastronomia, é importante ter em mente que os espaços ocupados por homens e mulheres se inscrevem em uma "ótica heteronormativa" e, por isso, são "desproblematizados" e passam desapercebidos, pois estão inclusos em núcleo de normas e valores pré-estabelecidos. Expelir tal heteronormatividade, recusar as certezas impostas e buscar fugir do discurso comum é não apenas um posicionamento intelectual, mas também político. Naira Scavone (2008, p. 2) traça uma breve retrospectiva sobre esse ponto da gastronomia no país:

No Brasil, a alta gastronomia fixa-se no eixo Rio-São Paulo, por mãos estrangeiras e para o acesso restrito de uma classe com poder aquisitivo para consumi-la. Entre as décadas de 80 e 90, a alta gastronomia na América toma outro rumo. Resumidamente, inicia-se uma febre sobre todos os aspectos que envolvem a gastronomia, incluindo a formação de profissionais em escolas nacionais, proliferação de restaurantes e programas de televisão com o tema da gastronomia, reinvenções e resgates das culturas locais através de adaptações de técnicas, produtos e pratos. Hoje, todos querem aprender mais sobre culinária, desfrutar dos prazeres dos grandes restaurantes, "devorar" os livros de chefs, abastecer-se nos supermercados com produtos que antes eram consumidos só por uma elite econômica.

Com isso, a gastronomia se populariza e, ao deixar a esfera elitizada, se torna uma "mania global". Demozzi (2011) discute a profissionalização da cozinha e a visibilidade do mundo gastronômico, gerando um ponto de concordância e outro de questionamento. Para a autora, há uma visão midiatizada sobre o ato de cozinhar, não coerente com o cotidiano. A representação que se tem da "[...] culinária oculta, ou ainda quando o faz transforma em espetáculo como o caso dos realities shows culinários Hell's Kitchen e Master Chef, 
os bastidores da cozinha, as dificuldades físicas e emocionais, os erros, enfim, o penoso caminho que é se tornar um chef de cozinha" (DEMOZZI, 2011, p. 17). Concorda-se que há uma associação com espetáculo; porém, sem entrar no mérito da profissão de chef, há sujeitos que vivem desigualdades na cozinha, devendo o debate começar pelas suas condições de trabalho.

Sobre o processo midiático no mundo contemporâneo, ele tem engendrado grandes transformações em diversos setores (GHILARDI, 2007, p. 5): "[...] ao (re)direcionar o modo de ver dos acontecimentos, ao mesmo tempo em que tem construído uma 'univocidade lógica' ou uma ilusão de unidade em torno de muitos aspectos comportamentais dos indivíduos e dos valores que subjazem às atitudes e pensamentos".

Os discursos midiáticos circulam na sociedade, sugerem transformações na vida cotidiana, na linguagem e também se transformam no tempo. Produzem efeitos de sentido que influenciam profundamente muitos aspectos do cotidiano. Analisá-los requer conhecimento do contexto sócio-histórico em que eles se inserem, assim como compreensão das relações entre diferentes formações discursivas que circulam nos veículos de comunicação. A mídia atua na construção do imaginário coletivo ao produzir imagens simbólicas e intermediar a relação entre os leitores e a realidade (GHILARDI, 2007, p. 5).

De acordo com autora, as revistas culinárias exercem um importante papel nesse cenário. Os homens posam ao lado de utensílios caros, diante de ingredientes exóticos e com predisposição para cozinhar receitas com o "selo de qualidade gourmet". A ideia é distanciar este preparo da comida daquele exercido cotidianamente pelas donas de casa e empregadas. A cozinha é ressignificada como um lugar mágico, cujo simbolismo sustenta a concepção de profissionais qualificados que preparam uma refeição "requintada". Diante disso, é essencial dizer que se termina por recorrer a uma noção sexista de qualificação das funções do homem e de desqualificação do trabalho das mulheres (NEVES, 2013), o que também pode ser diferenciado conforme a noção de classe, já que tal posição também contribui para o processo de distinção e qualificação dos sujeitos (BOURDIEU, 2007). Esse cenário não apenas subordina a tarefa de um grupo, como tende a "espetacularizar" a do outro.

Conforme Debord (1997) o conceito de espetáculo pressupõe um nível de separação. Se fosse considerado o teatro, por exemplo, esse distanciamento poderia ser visto entre os atores e o público ou entre o diretor da peça e os personagens. "É necessário lembrar que o espetáculo é uma metáfora e não a crítica superficial a quem assiste e a quem nele atua. É preciso compreender também que não se critica a dimensão visível como aquilo que se vê em propagandas, anúncios, comerciais" (GOBIRA; LIMA; CARRIERI, 2015, p. 265). O espetáculo é uma organização estética da sociedade que alimenta o jogo de interações sociais. Portanto, pode se manifestar como um mecanismo de distinção entre os sujeitos, quem produz e quem detém os meios de produção, uma separação indissociável do processo de espetacularização (DEBORD, 1997; GOBIRA; LIMA; CARRIERI, 2015).

Assim, "[...] o receber masculino é público, barulhento e a expectativa é o aplauso [...] a comida é feita em um processo de interação e ensinamento, no qual o anfitrião/ cozinheiro discorre sobre o que irá servir, fornecendo detalhes sobre a origem dos pratos e 
ingredientes" (BARBOSA, 2012, p. 194) - afinal, a cozinha possui um "requinte" e não é mais algo simplório. Em meio a esse movimento de "gourmetização", há um silenciamento a respeito do segregacionismo na cozinha doméstica. Ao vender, de forma desproblematizada, a ideia de que agora é preciso valorizar as práticas ali desenvolvidas, como se fosse apenas um selo capitalista de consumo (MARTENS; SCOTT, 2006), reforça-se um discurso sexista e racista.

\section{ESCOLHAS METODOLÓGICAS}

Segundo Kahlmeyer-Mertens et al. (2007, p. 16) "[...] a metodologia não procura soluções, mas escolhe as maneiras de encontrá-las, integrando os conhecimentos a respeito dos métodos em vigor nas diferentes científicas ou filosóficas". Nesse sentido, diante do objetivo apresentado, este estudo foi feito com base em um método indutivo de abordagem qualitativa, uma vez que permitiu a combinação das melhores práticas e métodos ao objeto e contexto, além de atentar à análise subjetiva dos fatos. Os dados foram produzidos por meio de entrevistas semiestruturadas individuais e em profundidade, o que permitiu partir de um roteiro e, ao mesmo tempo, estar aberto a novas questões.

Foram realizadas 17 entrevistas com empregadas domésticas, donas de casa (sem atividades profissionais fora de casa), patroas e patrões, um grupo com perfis variados, mas que, em conjunto, presenciou mudanças no âmbito da cozinha doméstica, mesmo que de formas distintas, além de poderem discorrer sobre a dinâmica das relações sociais de gênero nesse espaço, atentando para a atividade de cozinhar em diferentes perspectivas. É importante destacar que todas as empregadas domésticas trabalhavam em casas de família de classe média alta de Belo Horizonte, e que todos os patrões pertenciam a essa classe econômica. Os discursos são expressos no próximo item, com a devida identificação dos sujeitos com: nome (fictício), idade e grupo.

Para o tratamento dos enunciados dos fragmentos discursivos selecionados foi adotada a análise francesa do discurso (FIORIN, 2003), que se concentra em aspectos discursivos estruturais, sendo basicamente uma perspectiva linguística de análise. Ainda que o sujeito seja o responsável pelo que enuncia discursivamente, entende-se que fala a partir do lugar de um grupo social de referência, razão pela qual é adequado usar essa perspectiva considerando que patrões, patroas, donas de casa e empregadas domésticas trazem as posições de diferentes grupos sobre a ressignificação da cozinha doméstica. Partindo do pressuposto de que os sujeitos, ao enunciarem seus discursos, fazem uso de estratégias discursivas diversas, os procedimentos empregados para a análise do discurso neste artigo foram: a) identificação de enunciados explícitos e implícitos (subentendidos e pressupostos), bem como seus silenciamentos; b) análise lexical, na qual foram observados os léxicos e suas relações nos discursos; e c) reflexão e refrações linguísticas, que respectivamente mostram similaridades e diferenças do discurso em relação ao real.

\section{ANÁLISE E DISCUSSÃO DO MATERIAL EMPÍRICO}

A análise dos discursos permitiu chegar a cinco categorias discursivas: a) gastronomia, febre que a mídia "faz brotar"; b) a cozinha como vitrine: funcional, bonita e "branca"; 
c) a cozinha gourmet: uma questão de estética e convivência; d) a cozinha como trabalho (para a mulher) e como espetáculo (para o homem); e e) a cozinha do homem -prazerosa, narcisista e patriarcal.

\section{GASTRONOMIA, FEBREQUE A MÍDIA "FAZ BROTAR"}

A transição no modo como se pensa a cozinha e o ato de cozinhar muito se deve à influência da mídia, como será discutido nesta seção:

(1) A culinária de um tempo pra cá virou a queridinha da mídia, né? Hoje o programa de culinária é diferente. Ele não é um programa de culinária para a dona de casa, esse também ainda existe para uma cozinha simples, mas, hoje, é algo mais sofisticado e uma culinária que atinge todo mundo. (Jorge, 48 anos, patrão)

(2) Hoje existe uma valorização muito grande da cozinha, você pelo número de programas que existem e aí quando você entra nos supermercados gourmets que tem [...] Você pega o Verdemar e as outras redes que mesmo não sendo todo gourmet, você sempre tem uma ala gourmet, mais sofisticada que até então você não observava, com exceção de São Paulo ou quando você ia para o exterior. E aí entra o lado narcisista [...] Às vezes a pessoa compra uma coisa e nem sabe para que serve [...] Ela compra pra ter, simplesmente. Essa valorização é um "oba-oba", é midiática. (Fernando, 61 anos, patrão)

Há uma clara dimensão mercadológica envolvida e grande incentivo ao consumo, confirmando os argumentos de Martens e Scott (2006) e Bouty e Gomez (2013). Conforme Fernando, o "selo" gourmet tem alterado as expectativas de muitas pessoas que Ihes atribuem valor, demandando esta "qualificação". Embora ele perceba tal situação, dela faz parte. Ambos notam a mudança de posicionamento dos programas e sua capacidade de espelhar os desejos dos consumidores, o que reitera os argumentos de Floyd (2004). Ambos optam por este "selo" para adquirirem um status social requerido pelo seu grupo social de referência.

(3) Eu acho que essa questão de gourmet trouxe um interesse novo nas pessoas, porque programas de cozinha já tinha muitos, mas não erambadalados igual é hoje. Foi um interesse que a mídia conseguiu brotar no coração das pessoas. (Judite, 67 anos, dona de casa)

(4) A ideia de cozinha que a mídia passa é de uma cozinha perfeita. É uma visão que ela dá para vender eletrodomésticos, vasilhames e tal. Você vê muito isso nos programas, que por sinal eu assisto todos (risos). Eu gosto muito do GNT, então quinta-feira pra mim é um prato cheio. A Rita Lobo, adoro as receitas dela. O Claude eu não gosto muito não porque ele usa manteiga [...] Então é [...] Principalmente os programas do GNT e do TLC. Antigamente nem existiam muitos programas de culinária e hoje virou uma febre. Todo canal que você vai sempre tem alguma coisa de culinária [...] A doméstica que não trabalha fora de casa, sempre tem alguma coisa de culinária e isso tudo é para incentivar o consumismo. (Isadora, 54 anos, patroa) 
(5) Eu estava sem televisão lá em casa, aí [...] Estava sem sinal, mas agora voltou e eu voltei a assistir TV. Eu gosto de assistir o MasterChef de criança e o de adulto também [...] Muito bom. Eu gosto de ver e aprender as coisas que eles fazem, mas não é uma comida de todo dia [...] É uma comida mais chique. Só que eu não tento fazer as coisas que eles fazem (risos), porque é uma comida mais sofisticada, não é a comida simples que a gente faz. Eu acho muito bonito [...] É aquelas comidas de restaurante chique que eles preparam. Dá vontade cozinhar aquilo (risos). (Joana, 28 anos, empregada doméstica)

(6) Eu gosto desses programas. Quando vejo os homens cozinhando eu acho interessante, porque no meio eu não vejo muito isso. E aí eu acho interessante por serem eles. E também gosto desses programas devido às cozinhas serem bem elaboradas. Normalmente eles já vão com a comida quase preparada e eles vão só para finalizar. Eu gosto, acho muito interessante. Esses programas masculinos que eu vejo, normalmente eu não consigo replicar o que eles fazem, por serem pratos mais elaborados. Já o da Ana Maria, que eu vejo de vez em quando, eu acho mais fácil de replicar, por ser mais caseiro, mais fácil de fazer. (Mônica, 69 anos, dona de casa)

Nos fragmentos discursivos (3), (4), (5) e (6) há menções a programas populares, de cozinha do dia a dia, e a outro tipo de entretenimento, com um olhar distinto, trazendo uma espécie de "experiência" diferenciada. É possível perceber os temas da tradição e da inovação, atestando a uma ressignificação do que se entende por cozinhar. Fica implícitoque o discurso da cozinha gourmet exerce uma influência sobre os entrevistados, pois o reconhecem como um "selo" de diferenciação e qualificação. Judite chega a admitir explicitamente que a mídia "conseguiu brotar no coração" da sociedade uma nova demanda para algo que é um produto.

Além da evidente influência que os programas televisivos têm na vida dessas pessoas, chama a atenção a divisão,mesmo entre os "mais requintados". Os exibidos na TV aberta como o "MasterChef" são mais acessíveis e próximos. Os dos canais pagos são mais elaborados e, portanto, mais difíceis, embora impressionem os entrevistados. Embora haja um encantamento geral com a cozinha gourmet, distingue-se quem tem condições ou não de executar aqueles pratos do ponto de vista econômico e técnico. Além disso, é explícito o reconhecimento do ingresso da figura masculina nesse contexto, parte do "selo" de valorização da cozinha gourmet (BARBOSA, 2012).

\section{A COZINHA COMO VITRINE: FUNCIONAL, BONITA E "BRANCA"}

Consumir itens diversos da cozinha, como utensílios e reformas estruturais, também é uma forma de se apropriar do território e distingui-lo dos demais.

(7) Mudou muito, hoje em dia até o fogão você vê que hoje em dia não é mais fogão é CookTop. Ou seja, é muito diferente não tem nem mais trempe nem nada [...] Tudo o que é caro a sociedade valoriza. Eu tenho as panelas lecreuset que são caras. Ter essa questão de cozinha gourmet já é um indicativo das mudanças. Até a engenharia e a arquitetura já se adaptaram a essa 
questão de ter espaços gourmets nos prédios. Hoje é moda. Foi como um raio "gourmetizador" que nos atingiu. (Flávia, 29 anos, patroa)

(8) Hoje a cozinha é mais valorizada, até porque o mercado é maior. Hoje a quantidade de utensílios importados que existe é incrível. Antigamente, todo mundo batia uma clara em neves naquela [...] Espumadeira que a gente chamava, hoje tem batedeira da KitchenAid que custa $\mathrm{R} \$ 5.000,00$. Então assim [...] 0 mercado tem "bala" pra bancar isso. A gente vive em mundo capitalista (risos), o mundo capitalista não perdoa. A propaganda ela induz a pessoa a achar que aquilo é a maravilha. Aí vem a Air Fryer, o Polishop e fica te incentivando a comprar ummonte de "porcariada" e ai depois vê que aquilo não serve pra nada. (Jorge, 48 anos, patrão)

(9) Eu gosto de comprar esses utensílios mais gourmet, mas dá vontade de deixar tudo escondido porque a empregada não sabe lavar. Eu chego lá na loja, por exemplo, eu estou louca [...] Nessa aula que eu faço a mulher deu uma dica de uma frigideira e eu estou alucinada para comprar [...] A bichinha é cara, ai você põe isso na mão de empregada? Ela vai passar um Bombril [...] Então, assim [...] As coisas que eu compro, ah é comprei um picador de legumes super bacana, eu vou deixar na mão da empregada? Não! As coisas que eu tenho eu procuro deixar para eu usar. Então só eu que uso e pronto. Sabe aquelas facas de mesa? Fica na caixa [...] E eu vou falar quando usar, se não ela pica tomate, sabe? Então não dá [...] Se a cozinha vai ser gourmet, então eu é quem vou usar. (Luiza, 36 anos, patroa)

(10) A cozinha doméstica hoje é uma cozinha da alta gastronomia, temos equipamentos interessantes e tal. Lá em casa a minha cozinha doméstica durante os dias da semana ela funciona de uma forma, mas no final de semana [...] Ela vira literalmente uma cozinha de restaurante, uma cozinha [...] Uma cozinha industrial [...] Eu tenho uma cozinha gourmet. Eu acho que eu tenho utensílios interessantes, equipamentos interessantes. Inclusive (risos) eu e a menina lá em casa, nós temos os armários separados. Tem uns armários meus lá que ela não põe nem a mão (risos) [...] A faca que é minha, a faca do chef, que só eu corto com ela. Então assim, tem coisas separadas. (Jorge, 48 anos, patrão)

Os fragmentos discursivos (7), (8), (9) e (10) vem do grupo dos patrões. Ao dizer que um "raio gourmetizador nos atingiu", a análise lexical revela que Flávia fala a partir de um grupo, a classe média alta, envolvida e influenciada pelo gourmet, ainda que tal "raio"seja uma moda, ela demonstra interesse pela ressignificação da cozinha. Cita duas marcas específicas, deixando demarcado que se "é caro a sociedade valoriza". Jorge segue a mesma linha e pontua três marcas, sugerindo que a cozinha está além de um conjunto de utensílios modernos e deve ser pensada como um "processo manual", embora admita que a valorização da cozinha tenha o suporte da mídia. Já Luiza demonstra não só interesse, como também diferenciaos produtos que ela usa dos que a sua empregada pode usar, pois esta seria incapaz de manusear os itens "gourmet". No fragmento discursivo (10), Jorge repete o mesmo discurso de Luiza, porém ele se denomina "chef". Ele é explícito quanto ao fato de que quando assume a cozinha aos finais de semana, ela se transforma em algo superior do que o existe durante a semana, com a empregada, o que reforça a desqualificação profissional (BRUSCHINI; RICOLDI, 2012; DEMOZZI, 2011; SCAVONE, 2008), técnica (BOUTY; GOMEZ, 2013; GHILARDI, 2007; MARTENS; SCOTT, 2006) e social (MEAH, 
2014; GIARDI, 2009; FLOYD, 2004) da cozinha ocupada cotidianamente por umamulher - e empregada.

É problemático constatar tamanha distinção nessas relações socioprofissionais. Mesmo que utilizem de artifícios para silenciar que consideram as empregadas sujeitos subordinados e incompetentes, fica nítido um discurso de classes, em que parece inexorável um novo arranjo. Esta situação pode ser vinculada ao debate sobre distinção social feito por Bourdieu (2007), já que a busca pela "superioridade de classe" faz com que se procure a distinção do estilo de vida e a demarcação da condição ou não de privação. Esses aspectos sugerem a ressignificação da cozinha com base em novos modos de apropriação. É oportuno questionar: a cozinha está realmente passando por transformações? Quais seriam elas?

(11) A cozinha mudou muito. Eu acho ótimas essas cozinhas gourmet. Extremamente funcionais e eu gosto de estar em lugares bonitos, porque isso me inspira. Você vai trabalhar em um lugar que está todo feio? Não dá, né?! Então isso te incentiva. Essa ideia de gourmet acaba sendo uma especialidade e isso leva a uma valorização da cozinha no sentido até de criar cursos de gastronomia. (Isadora, 54 anos, patroa)

(12) Mudou muito, tecnologia e arte na cozinha. Hoje você tem uma estrutura de cozinha que facilita o trabalho da mulher em muita coisa. Eu ainda vejo que o homem encara na maioria das vezes a ida dele na cozinha como um favor de cooperação com a mulher, mas existem homens que é porque se sentem vocacionados. Assim, existem alguns [homens] que cozinham diariamente, mas a maioria vai lá [na cozinha], se apropria, dá o seu show e depois deixa tudo como sempre". (Juliana, 69 anos, patroa)

(13) Hoje a cozinha é mais sofisticada. Existem muitos homens que são chefs de cozinha, muitas mulheres brancas, de cor da pele branca que adentraram nesse meio, então eu acho que assim hoje em dia isso já muito misturado. A cozinha saiu desse patamar de [...] Vamos colocar assim a cozinha deixou de ser o lugar da senzala e passou a ser [...] Falando rasgado assim mesmo [...] E passou a ser um lugar onde as pessoas, não só os negros, ex-escravos vão se reunir [...] Passou a ser um lugar de integração. (Flávia, 29 anos, patroa)

Isadora atribui às transições pelas quais a cozinha passa às possibilidades da cozinha gourmet. Ele a reconhece como um "selo" de qualidade e traz à tona o percurso semântico da cozinha como espaço de inspiração. Juliana também reconhece a "funcionalidade" dessa cozinha:primeiramente no sentido de facilitar "o trabalho da mulher", restringindo a atuação do homem a um "favor de cooperação" (FLOYD, 2004). Em seguida, confirma que o movimento gourmet funciona como um palco para que o homem se aproprie da cozinha sazonalmente e, depois, reitere as práticas patriarcais. Já Flávia tenta enunciar um discurso progressista, mas depois explicita seu racismo ao relacionar "a cozinha sofisticada" à "presença de pessoas brancas", que deixou de ser o "lugar da senzala". Além de explicitar um aspecto ideológico, fica refratado que para ela é condição essencial para a valorização da cozinha a presença de pessoas brancas, um discurso racista e classista. 


\section{A COZINHA GOURMET: UMA QUESTÃO DE ESTÉIICA E CONVIVÊNCIA}

Nesta seção, inicialmente se nota o percurso semântico da cozinha atual como espaço de convivência:

(14) Antigamente a cozinha era simplesmente um espaço para fazer a comida e colocar na mesa lá fora. Hoje, hoje em dia, eu acho que a cozinha passou a ser um espaço de convívio de amigos. Antes tínhamos a sala de visita, quer dizer, a pessoa entrava ali na sala, e dali mesmo ela voltava. Hoje não, hoje a visita vai na sala, depois pra sala de jantar e hoje já está lá dentro da sua cozinha. Hoje ela tem um espaço mais central na casa. (Jorge, 48 anos, patrão)

(15) A cozinha está saindo da cozinha, né? Tá indo pra varanda [...] Para um espaço de convivência maior, com a ideia do gourmet. Hoje a cozinha é linda, antes ela era largada. Hoje não [...] Essas cozinhas são lindas, tem uma questão de te atrair para ela. E eu acho que os programas de televisão são os responsáveis, não só pela culinária, mas também por essa parte da decoração [...] Com o gourmet, por exemplo, a pessoa está levando a cozinha para dentro da sala. (Luiza, 36 anos, patroa)

(16) Hoje a cozinha é mais valorizada, antes ela não tinha tanto valor [...] A cozinha, as cozinheiras, a comida [...] Hoje não é só pra encher barriga. Hoje você vê que as cozinhas estão mais vistosas. 0 povo hoje quer comer coisa boa, coisa gostosa, quer saborear. Antigamente era sentar, almoçar, jantar e pronto. Hoje não, você senta, conversa. (Alice, 35 anos, dona de casa)

Existe uma distinção clara entre as cozinhas: Jorge trabalha com a ideia de que ela deixou de ser um local apenas familiar para abrigar encontros entre amigos, uma "sala de visitas". Ao defini-la como "espaço mais central da casa", ele explicita que as transformações ali vivenciadas redimensionam a importância deste espaço. Luiza já assegura que "a cozinha está saindo da cozinha", refletindo a valorização que ela dá a esse "novo" espaço quando diz que "hoje a cozinha é linda, antes ela era largada". Alice acrescenta que hoje a cozinha recebe um valor maior, pois a alimentação deixou de ser sua única atividade: há outros "prazeres" envolvidos, como a recepção de pessoas e a convivência, corroborando Meah (2014).

(17) É um gosto inexplicável, você pega, por exemplo, um pão com azeite trufado, não tem gosto de nada que a pessoa já tenha comido na sua vida. Hoje a cozinha tem uma posição mais central na vida das pessoas. A cozinha era um lugar que era da empregada ou da dona da casa [...] Aquele lugarzinho mais [...] Afastado da casa, né? Era dentro da casa, mas era pouco frequentado. Hoje a cozinha tem glamour, né? (Fernando, 61 anos, patrão)

(18) Quando a gente passa em uma loja de conveniência, por exemplo, tudo que é o diferente para a cozinha você quer ter em casa. Hoje todo mundo quer levar o moderno da cozinha para casa. Eu também acho que hoje as pessoas estão mais na cozinha. Antigamente era da sala para lá, e hoje as visitas são trazidas para a cozinha. Mostrando que eu estou fazendo. Todo mundo quer ver como foi feito aquele prato bacana. A cozinha era um espaço que às vezes as pessoas conheciam a sua casa e não conheciam a cozinha. Hoje é muito 
comum convidar para ir à cozinha. Isso é porque, além de a cozinha estar mais moderna, antes a cozinha era o lugar em que estava a empregada, e aí ela tinha que ficar lá no cantinho. Hoje quando você vai receber uma visita, a empregada também tem que se arrumar para esperar, para que fosse possível ver a cozinha. Em uma casa que eu trabalhei o meu uniforme do dia a dia era um e o de visita era outro(risos). Eles querem que a empregada também esteja mais arrumadinha, mais moderna. (Fernanda, 48 anos, empregada doméstica)

(19) Antigamente a cozinha era escondida, só mesmo alguém muito chegado que você chamava e ia para a cozinha, certo? Então era um lugar melhor, não tinhaaquela limpeza que hoje se mostra nessas cozinhas modernas [...] Hoje a pessoa faz questão: "vem ver a minha cozinha". Ela é uma sala de visitas (Judite, 67 anos, dona de casa)

Fernando divide sua fala em duas partes. Primeiro nota-se a ênfase na constituição dos alimentos e seu modo de preparo. Ele traz o tema da comida natural e o da comida industrializada, relacionado às possibilidades que a cozinha atual traz no sentido de variedade e diversidade de combinações (BOUTY; GOMEZ, 2013). Em um segundo momento, enuncia que a cozinha sempre foi um espaço da casa em que era dispensável dar valor, por ser o local da dona de casa e da empregada doméstica, ratificando o fragmento discursivo (13).

Ao enunciar que atualmente a "cozinha tem glamour", elerefratauma valorização a partir do momento em que percebe uma transição na constituição concreta e simbólica daquele espaço, além de deixar subentendido que a cozinha assume um status diferenciado na medida em que abriga outras formas de apropriação (FLOYD, 2004). De modo complementar, Bourdieu (2007) diria que tais modos de se assumir o território estariam relacionados à estrutura do capital e a trajetória social do indivíduo, como se a relação de posse e o volume de tal apropriação também estivesse refletido em questões de classe.

Fernanda fornece um exemplo dessa questão ao afirmar que já trabalhou em casas em que, em dias de visitas, até as empregadas tinham que se arrumar de forma diferente, pois agora os convidados são levados à cozinha. Ela admite que a cozinha passou por transformações e a ela foram atribuídos itens que sustentam essa transição, pois "[...] hoje todo mundo quer levar o moderno da cozinha para casa". Por fim, Judite corrobora os enunciados e acrescenta que hoje há um interesse em assumir a cozinha como uma "sala de visitas". Em conjunto, o que é sugerido é que há inúmeras possibilidades de se ressignificar aquele espaço, e não apenas pelas famílias de classe média alta. Nesses termos, é basilar compreender que muito dessa transição está ligada aos modos de apropriação e isso se reflete diretamente em uma figura que antes se distanciava da cozinha, o homem.

\section{A COZINHA COMO TRABALHO (PARA A MULHER) E COMO ESPETÁCULO (PARA O HOMEM)} cozinha:

Os fragmentos discursivos (20), (21) e (22) mostram distintas apropriações na

(20) O homem se apropria da cozinha no dia do churrasco (risos), acham que a mulher não sabe. 0 dia de receber os amigos dele é ele que vai querer fazer 
tudo para eles pensarem que foi ele quem fez. Eu tenho um sobrinho que é assim, sábado a cozinha é dele, mas só quando os amigos estão por perto. (Fernanda, 48 anos, empregada doméstica)

(21) A mulher vê a cozinha como um trabalho, né [...] O dela, o trabalho dela [...] (silêncio). É, eu acho que isso foi naturalizado, veem desde antigamente. Já o homem se apropria com prazer [...] Tanto que ele faz só quando ele quer, sem a menor obrigação, ele faz por prazer. (Luiza, 36 anos, patroa)

(22) A mulher sempre cozinha pensando em quem vai comer, o homem muito mais pra satisfazer o ego, pra fazer uma coisa bacana, quer fazer um prato bacana, quer impressionar. Geralmente o amigo que não gosta de cozinhar, ele encosta ali no balcão e fica só no ohhh [...] (risos). Fica só impressionado com o que você está fazendo e elogiando. E a mulher não, ela cozinha por amor mesmo. Acho que a mulher tem o dom, a necessidade mesmo, a vontade dela de transparecer amor. (Jorge, 48 anos, patrão)

Fernanda questiona o modo como seu sobrinho se apropria e se dispõe a estar na cozinha. Assim como Luiza, que condena a prática, mas não faz grandes problematizações. Jorge chega a afirmar que a mulher possui a "necessidade" de cozinhar para transparecer amor, ao contrário do homem, que cozinha para "impressionar" com a expectativa de aplauso, como referenciado por Barbosa (2012). O enunciador naturaliza a diferença entre papeis e reitera que cozinhar, para um homem, não passa de um "espetáculo", em que o ator principal tem livre poder de escolha para decidir quando e como encenar.

(23) Às vezes o Maurício, meu marido, vai fazer comida e ele fala assim "hoje eu vou fazer", eu já vi que não é pra eu ficar dando palpite (risos) Quando ele fala assim [...] Já quer dizer que ele está fazendo e que não quer palpite. Eu não, eu gosto de opinião, eu gosto de ajuda. Às vezes eu vejo que homens gostam de mostrar que estão aprendendo a fazer. (Alice, 35 anos, dona de casa)

(24) A mulher sempre teve aquele "restaurantezinho" da comida caseira, comidinha gostosa, e o homem aquela cozinha mais espetacular assim [...] Mais impressionante. São diferentes, são completamente diferentes os modos de apropriação. Eu acho que o homem cozinha pra satisfazer a ele, pra impressionar, esse é sempre um ponto que eu vejo [...] 0 homem que cozinha sempre gosta de fazer um jantar, receber uns amigos, mostrar que sabe um prato diferente, gosta de ver as pessoas ficando impressionadas com o fato de ele saber cozinhar. $E$ a mulher não, a mulher ela gosta de cozinhar para o filho, para o marido, não tem essa necessidade de cozinhar para as amigas, são poucas. 0 homem entra muito mais dentro desse contexto do que a mulher. Ele é a novidade e aí você acaba se tornando uma coisa diferente, e o diferente é sempre mais interessante. (Jorge, 48 anos, patrão)

(25) Eu acho que as mulheres se apropriam mais da cozinha pelo lado do fazer. Elas têm mais interesse assim [...] Pela lida do fazer, do executar. 0 homem ele gosta, mas ele gosta muito do [...] Degustar. Eu tenho alunos que gostam de por a mão na massa, mas não é toda aula não (risos). (Fernando, 61 anos, patrão) 
Fica explícito que Alice reconhece na fala de seu marido a "benevolência" de alguém que, eventualmente, "se dispõe a ajudá-la". Mesmo "se dispondo", ele se nega a receber palpites, já que se reconhece como um conhecedor daquele assunto e não demandará qualquer auxílio. Essa situação recupera o tema da hierarquia de gênero, bem como a da masculinidade, pois mesmo fazendo a função "dela", ele assume possuir os conhecimentos necessários (MEAH, 2014). Já Fernando chega a falar em um "interesse" maior na cozinha por parte das mulheres. Jorge silencia sobre um conjunto de relações e os tipos de ganho que cada uma das partes oferece, sugerindo que o papel da mulher é secundário no momento em que compartilha o espaço da cozinha com um homem, atestando as discussões de Pateman (2010) e de Ribeiro e Hanashiro (2016).

(26) É impressionante a quantidade de homens que gostam e admiram a cozinha gourmet. Eles querem se envolver mais [...] Pela possibilidade de eles poderem ir para a cozinha, para não ter aquilo de que cozinha é só da mulher. A comida gourmet é de vez em quando, né? Então é bom. A gente tende a não gostar da rotina, se passar a ser uma obrigação. (Judite, 67 anos, dona de casa)

(27) Hoje você fala "você vem que eu [...] Vou fazer um jantar diferente" [...] É uma forma de encantar os convidados. O gourmet é um selo que valoriza [...] Os apartamentos mais novos já vêm com uma nova proposta [...] Varanda gourmet, churrasqueira na varanda, cozinha integrada com a sala [...] Hoje os quartos estão sendo comprimidos para [...] Liberar espaço para a cozinha. (Henrique, 48 anos, patrão)

(28) 0 que eu tenho visto nos círculos de amizade são homens assumindo a cozinha [...] Querendo fazer um prato diferente ou o mesmo prato, mas de uma forma diferente que ele aprendeu e aí eles começam a competir informalmente [...] E falam tipo "oh, esse ano eu vou trazer uma novidade [...] Um prato que eu vi lá na Espanha" [...] Então, nesses encontros quem tem aparecido são os homens na cozinha, se for uma mulher aí o pessoal vai falar "aí não vale [...] quero ver um homem fazer". É uma espécie de show, ele está ali se mostrando, fazendo uma coisa que a maioria dos meus colegas não sabe. (Lucas, 42 anos, patrão)

Judite afirma que a cozinha gourmet não é para todo dia. Portanto, por ser uma inovação, é vista com bons olhos. Henrique e Lucas enunciam um discurso da satisfação do ego e de certa "virilidade" que esta apropriação pode trazer: não medem palavras para deixar claro que o "homem gourmet" quase sempre está envolvido em um jogo duplo para se satisfazer e levar vantagem sobre os demais, como um esporte, uma competição, confirmando a perspectiva de Bouty e Gomez (2013). Quando Lucas enuncia a frase "aí não vale... Quero ver um homem fazer", fica subentendido que essa solicitação só é feita porque se considera que aquele é um papel feminino; portanto, se uma mulher realizar não há nada o que valorizar. Naturalizar essas situações é o mesmo que defender um aspecto ideológico que contribui para a divisão sexual do trabalho (HIRATA; KERGOAT, 2007). 


\section{A COZINHA DO HOMEM - PRAZEROSA, NARCISISTA E PATRIARCAL}

Os fragmentos discursivos (29), (30), (31) e (32) constroem estereótipos sexistas:

(29) Quando se fala assim "ah, vamos cozinhar!", os homens pensam logo que é arroz, feijão, uma farofinha e aí isso não é muito atraente para ele. Agora quando é a cozinha gourmet [...] "Opa, vou inventar alguma coisa". Então é acho que essa palavra nova, gourmet, está atraindo mais os homens. É a oportunidade que ele tem de fazer algo melhor [...] Um diferencial (risos). Eles gostam de receber para mostrar que sabem fazer, mas de vez em quando. Eu vejo que os homens gostam mais dessa cozinha gourmet e vejo que as mulheres gostam mais da tradicional. (Fernanda, 48 anos, empregada doméstica)

(30) É bem nítido que os homens não têm apelo nenhum pela comida cotidiana: bife, batata frita, feijão e arroz. Nenhum homem tem a menor disposição para fazer essa comida do dia a dia e acho que nunca vai ter. 0 movimento gourmet traz diversão, prazer. (Henrique, 48 anos, patrão)

(31) Os homens gostam é do gourmet. O homem apesar de toda a evolução ainda continua muito machista. Então quando ele vai para essas cozinhas gourmet ele não se sente uma mulher, mas [...] "O" homem. É diferente da condição de trabalho em uma cozinha comum. Eles vão para a cozinha, mas em ocasiões especiais. Eles não se apropriam da cozinha no dia a dia. (Isadora, 54 anos, patroa)

(32) Tem o lado de você fazer junto com a sua família uma coisa diferente, mas tem o lado também narciso [...] Em que você vai trazer um ingrediente que você viu não sei onde em uma viagem que você fez é [...] E aí tá lá o narciso mostrando a beleza que ele fez, mas é uma beleza que não pode ser dividida e que vai inflar o ego dele. Tem o lado patológico da cozinha também, né? A gente vê muito isso nos gourmet de primeira hora. (Fernando, 61 anos, patrão)

Fernanda começa sua fala retomando o debate sobre a cozinha pública e a privada. Interessante constatar a descrição que ela faz dos homens em uma cozinha gourmet, pois existe uma associação entre esse "selo" e uma qualificação superior. Além disso, a ideia do gourmet sugere a ocupação eventual e isso os exime de permanecer naquele espaço. Jorge assume que a cozinha não passa de um "divertimento". Como já visto, ele se mostra um ávido consumidor do selo gourmet, pois além de encará-lo como uma forma de valorização, permite construir um espaço mais intimista, no que corrobora as perspectivas de Martens e Scott (2006) e Bouty e Gomez (2013). Ademais, usa o símbolo gourmet para legitimar uma apropriação momentânea, esquivando-se do peso da obrigatoriedade de cozinhar (FLOYD, 2004), ressignificandoa cozinha como "palácio do prazer" (MEAH, 2014, p. 671).

Fica explícita nos quatro discursos uma motivação diferente para que o homem se aproprie da cozinha. Henrique evidencia o único objetivo do homem na cozinha, o prazer. Fica refratado que, para ele, é impossível pensar em um homem que se disponha a cozinhar cotidianamente, deixando subentendido que há, para eles,uma escolha - pois não Ihes cabe a obrigação. Isadora parece confirmar esta visão ao dizer que "os homens gostam é do gourmet", pois ele só ocorre em "ocasiões especiais". Isadora adiciona o tema da valoriza- 
ção e deixa explícito que as condições de trabalho são distintas, sugerindo relações sociais nesse espaço. Fernando corrobora os demais, mas denomina os sujeitos de quem falade "narcisos" ou "gourmet de primeira hora". Tal definição rotula justamente quem busca um rótulo, já que gourmet refletea qualidade superior, que permite se distinguir dos outros, e a possibilidade de apresentar ao mundo suas qualidades enquanto "chef" de cozinha de final de semana.

(33) Eu acho que o movimento gourmet vem com a saída da mulher da cozinha, primeiro. Porque até então, quando a mulher assumia esse papel de ser dona de casa, cozinheira e de ficar restrita a esse espaço [...] É [...] O homem não tinha muito espaço e a culinária que existia era uma culinária tradicional. Como eu disse, o advento do movimento gourmet tem haver com a entrada do homem na cozinha e tem haver também com o mercado globalizado. (Jorge, 48 anos, patrão)

Quando Jorge diz que o movimento gourmet está associado à "saída" da mulher da cozinha, ele deixa implícito que o selo e o reconhecimento que vem com ele é algo, exclusivamente, destinado ao homem. Dizer que "o homem não tinha muito espaço" é uma tentativa de vitimização de sujeito que é o ponto principal para a manutenção do sistema patriarcal e opressor - o homem. Não reconhecer isso é compactuar com a permanência de práticas de subordinação e inferiorização conforme o sexo (HIRATA; KERGOAT, 2007).

\section{CONSIDERAÇÕES FINAIS}

Com o objetivo de analisar a ressignificação material e simbólica pela qual a cozinha doméstica vem passando, este estudo foi feito com base em um método indutivo de abordagem qualitativa a partir de entrevistas semiestruturadas com empregadas domésticas, donas de casa, patroas e patrões. Em diferentes níveis, foi possível constatar a indícios que comprovam tal ressignificação. Os entrevistados se mostraram influenciados pelo movimento gourmet, particularmente pela mídia. É preciso pontuar que o alcance de tais conceitos é distinto conforme as classes socioeconômicase, embora o alvo principal seja a classe média alta, os estímulos são dirigidos a todos os que podem se tornar consumidores, já que é inegável que a cozinha doméstica e o ato de cozinhar vêm passando por metamorfoses notáveis.

A dimensão materialda ressignificação da cozinha doméstica esteve evidente nos fragmentos discursivos que associaram a cozinha gourmet a algo que deve ser consumido por todos, mesmo quem eventualmente não puder fazê-lo, dado que se procura "plantar" o desejo de um novo espaço. Nesse sentido, a cozinha é reapresentada midiaticamente com inovações arquitetônicas e com artefatos diversos. Objeto de intenso desejo, é funcional, limpa, bonita, sofisticada, e a ela se devem ajustar todos os que por ali circularem, havendo espaços físicos distintos, inclusive, para os utensílios da cozinha cotidiana e os artefatos gourmet, só usados pelo chef em ocasiões especiais.

A dimensão simbólica da ressignificação da cozinha esteve relacionada, principalmente, à presença cada vez maior dos homens e à possibilidade de fazer desse ambiente um 
espaço de convivência social, já que agora ele tende a ser estruturado para ter um caráter mais intimista. Sendo um lugar espetacularizado, não se deseja nele qualquer convivência, mas uma convivência "qualificada" - isto é, sem empregados. No caso de estes estarem presentes, precisam "combinar" com ambiente gourmet, estando "esteticamente impecáveis". Para as mulheres, contudo, a cozinha, mesmo ressignificada, permanece sendo um espaço compulsório de trabalho doméstico cotidiano, ao passo que para os homens, trata-se de um espaço que eventualmente frequentam para promover "espetáculos gastronômicos" que precisam de utensílios sofisticados, ingredientes selecionados, plateia e, principalmente, aplausos. A cozinha ressignificada, assim, é o lugar do homem, que prepara comida longe das obrigações cotidianas, femininas e, por isso, associada, de forma narcísica, ao seu próprio prazer patriarcal.

As principais contribuições problematizam a complexidade da nova cozinha doméstica gourmet para além da sua materialidade. Os atributos dessa nova cozinha investem em um falso antagonismo - de forma velada, violenta e perversa - entre tradição, simplicidade e feminino,e inovação, sofisticação e masculino, em um espaço que só foi recentemente valorizado à medida que os homens quiseram ocupá-lo, transformando-o, de privado e íntimo, em público e espetacularizado. A assertiva "a expectativa é o aplauso", presente em vários depoimentos, reforça o pressuposto de que os homens só se interessaram pela cozinha e a ressignificaram como gourmet ao ocultar questões históricas da sociedade brasileira. Eles não assumem que este espaço só os atrai à medida que se distancia da rotina e da obrigatoriedade de cozinhar, mantendo, para eles - e apenas para eles - a herança patriarcal de poder escolher se, como, quando, onde e para quem cozinhar.

\section{REFERÊNCIAS}

BARBOSA, L. Os donos e as donas da cozinha. In: FREITAS, M. E.; DANTAS, M. (orgs.). Diversidade sexual e trabalho. São Paulo: Cengage Learning, 2012, p. 171-201.

BOURDIEU, P. A distinção: crítica social do julgamento. São Paulo: EDUSP, 2007.

BOUTY, I.; GOMEZ, M.-L. Creativity in haute cuisine: strategic knowledge and practice in gourmet kitchens. Journal of Culinary Science \& Technology, v. 11, p. 80-95, 2013.

BRUSCHINI, C.; RICOLDI, A. M. Revendo estereótipos: o papel dos homens no trabalho doméstico. Estudos Feministas, v. 20, n. 1, p. 259-287, 2012.

DEBORD, G. A sociedade do espetáculo. Rio de Janeiro: Contraponto, 1997.

DEMOZZI, S. F. Cozinha do cotidiano e cozinha profissional: representações, significados e possibilidades de entrelaçamentos. Revista História: Questões \& Debates, Curitiba, n. 54, p. 103-124, 2011. Disponível em: http://www.historiadaalimentacao.ufpr.br/artigos/ Artigos_PDF/Sabrina\%20Demozzi.pdf. Acesso em 6 dez. 2016.

DÓRIA, C. A. Flexionando o gênero: a subsunção do feminino no discurso moderno sobre o trabalho culinário. Cadernos Pagu, v. 39, 2012, p. 251-271.

FIORIN, J. L. Linguagem e ideologia. 7. ed. São Paulo: Ática, 2003. 
FLOYD, J. Coming out the kitchen: texts, contexts and debates. Cultural Geographies, v. 10, p. 61-73, 2004.

GHILARDI, M. I. Representações do gênero masculino: homens em revistas de culinária. In: CONGRESSO DE LEITURA DO BRASIL, 16., 2007, Campinas. Anais... Campinas: Unicamp, 2007.

GIARD, L. Artes de nutrir. In: CERTEAU, M.; GIARD, L; MAYOL, P. A invenção do cotidiano - 2. Morar, cozinhar. 9. ed. Petrópolis: Vozes, 2009.

GOBIRA, P.; LIMA, O.; CARRIERI, A. P. Uma "sociedade do espetáculo" nos/dos estudos organizacionais brasileiros: notas críticas sobre uma leitura incipiente. Cadernos EBAPE. BR, v. 13, n. 2, p. 256-285, 2015.

HIRATA, H. Reestruturação produtiva, trabalho e relações de gênero. Revista Latinoamericana de Estudios del Trabajo, v. 4, n. 7, p. 5-27, 1997.

HIRATA, H.; KERGOAT, D. Novas configurações da divisão sexual do trabalho. Cadernos de Pesquisa, v. 37, n. 132, p. 595-609, 2007.

IPIRANGA, A. S. R.; LOPES, L. L. S.; SOUZA, E. M. A experiência estética nas práticas culinárias de uma organização gastronômica. Organizações \& Sociedade, v. 23, n. 77, p. 191-210, 2016.

KAHLMEYER-MERTENS, R. S.et al. Como elaborar projetos de pesquisa: linguagens e método. Rio de Janeiro: FGV, 2007.

LEFEBVRE, H. The production of space. Oxford: Blackwell, 1991.

MARTENS, L.; SCOTT, S. Under the kitchen surface. Domestic products and conflicting constructions of home. Home Cultures, v. 3, n. 1, p. 39-62, 2006.

$\mathrm{MEAH}, \mathrm{A}$. Reconceptualizing power and gendered subjectivities in domestic cooking spaces. Progress in Human Geography, v. 38, n. 5, p. 671-690, 2014.

NEVES, M. A. Anotações sobre trabalho e gênero. Cadernos de Pesquisa, v. 43, n. 149, p. 404-421, 2013.

. Trabalho e gênero: permanências e desafios. Sociedade e Cultura, v. 9, n. 2,p. 257-265, 2006.

PATEMAN, C. Garantir a cidadania das mulheres: A indiferença e outros obstáculos. Revista Crítica de Ciências Sociais, v. 89, p. 29-40, 2010.

The sexual contract. Cambridge: Polity Press; Stanford University Press, 1988.

RIBEIRO, L. M. B. B.; HANASHIRO, D. M. M. Gênero e marxismo: a abordagem das relações sociais entre os sexos. In: CARRIERI, A. P.; TEIXEIRA, J. C.; NASCIMENTO, M. C. R. (orgs.). Gênero e trabalho: perspectivas, possibilidades e desafios no campo dos estudos organizacionais. Salvador: UFBA, 2016. p. 95-127.

SCAVONE, N. O super chefe e a menina prodígio: as posições ocupadas pelo gênero na gastronomia profissional. In: FAZENDO GÊNERO: CORPO, VIOLÊNCIA E PODER, 8., 2008, Florianópolis. Anais... Florianópolis: UFSC, 2008. 
SILVA, E. B. Fazendo gênero na cozinha: tecnologias e práticas. Revista Latinoamericana de Estudios del Trabajo, v. 4, n. 7, p. 29-53, 1997.

TACHINO, T. Genre, ideology, and knowledge in academic research and public policy. Ling. (dis)curso, v. 10, n. 3, 2010, p. 595-618.

WELZER-LANG, D. Os homens e o masculino numa perspectiva de relações sociais de sexo. In: SCHPUN, M. R. (org.). Masculinidades. São Paulo: Boitempo, 2004, p. 107-128.

Data de Submissão: 14/08/2016.

Data de Aprovação: 25/05/2017. 